\title{
Pengaruh Terapi Bekam Basah terhadap Perubahan Tekanan Darah pada Pasien Hipertensi
}

\author{
Dwi Yunita Rahmadhani \\ Prodi SI Keperawatan dan Profesi Ners \\ Email:dwi.azkaya@gmail.com
}

Submitted : 30/08/2021

Accepted: 10/09/2021

Published: 15/09/2021

\begin{abstract}
Non-Communicable Diseases (PTM) is one of the world's health problems that is still a concern in the world of health because it is one of the causes of death. Hypertension is a condition where systolic blood pressure is $140 \mathrm{mmHg}$ or higher and diastolic blood pressure is $90 \mathrm{mmHg}$ or higher. The cause of hypertension is due to abnormal water and salt retention, sensitivity to angiostensin, obesity, hypercholesteroemia, disturbed emotions / stress and smoking. One of the non-pharmacological therapies that can be used for the management of hypertension is to use wet cupping therapy. The purpose of this study was to analyze the effect of wet cupping on the blood pressure of hypertensive patients.Blood pressure as the dependent variable and wet cupping as an independent variable. This study uses a Pre Experimental Design study with "Two Group Pre Test and Post Test Design". The sample consisted of 20 people with hypertension with 10 respondents in the intervention group and 10 respondents in the control group in the Al-Thaf Nursing home in Jambi City on March to July 2021 with the Purposive Sampling technique. He statistical test carried out is to use paired t-test. From the results obtained $p$ value systolic blood pressure $=0,000$ and $p$ value diastolic blood pressure $=$ 0,000.The conclusion of this study is that there is an effect of wet cupping therapy on blood pressure stabilization in hypertensive patients in the city of Jambi
\end{abstract}

Keywords: hypertension, wet cupping therapy

\begin{abstract}
Abstrak
Penyakit Tidak Menular (PTM) adalah salah satu masalah kesehatan dunia yang masih menjadi perhatian dalam dunia kesehatan karena merupakan salah satu penyebab dari kematian. Hipertensi merupakan kondisi dimana jika tekanan darah sistole $140 \mathrm{mmHg}$ atau lebih tinggi dan tekanan darah diastole $90 \mathrm{mmHg}$ atau lebih tinggi. Penyebab terjadinya hipertensi disebabkan karena retensi air dan garam yang tidak normal, sensitifitas terhadap angiostensin, obestitas, hiperkolesteroemia, emosi yang terganggu/ stress dan merokok. Salah satu terapi nonfarmakologi yang dapat digunakan untuk penanganan hipertensi adalah dengan menggunakan terapi bekam basah. Tujuan penelitian ini adalah untuk menganalisis pengaruh bekam basah terhadap tekanan darah pasien hipertensi. Tekanan darah sebagai variabel dependen dan bekam basah sebagai variabel independen. Penelitian ini menggunakan penelitian Pre Experimental Design dengan "Two Group Pre Test and Post Test Design". Sampel berjumlah 20 orang penderita hipertensi dengan 10 responden kelompok intervensi dan 10 responden kelompok kontrol di Rumah Perawatan Al-Thaf Kota Jambi pada bulan maret sampai bulan Juli 2021 dengan teknik Purposive Sampling. Uji statistik yang dilakukan adalah dengan menggunakan uji paired t-test. Dari hasil didapatkan $\mathrm{p}$ value tekanan darah sistole $=0,000$ dan $\mathrm{p}$ value tekanan darah diastole $=0,000$.Kesimpulan dari penelitian ini adalah terdapat pengaruh terapi bekam basah terhadap stabilisasi tekanan darah pada pasien hipertensi di Kota Jambi.
\end{abstract}

Kata Kunci : hipertensi, terapi bekam basah

\section{PENDAHULUAN}

Hipertensi sering disebut the silent

killer karena gangguan ini merupakan suatu keadaan tanpa gejala, tetapi jika dibiarkan dan berlangsung dalam waktu yang lama dapat mengakibatkan kerusakan yang permanen pada organ-organ tubuh vital 
seperti jantung, ginjal dan otak. Hipertensi adalah kondisi dimana jika tekanan darah sistole $140 \mathrm{mmHg}$ atau lebih tinggi dan tekanan darah diastole $90 \mathrm{mmHg}$ atau lebih tinggi (Syamsyudin, 2011).

Hipertensi saat ini masih menjadi masalah utama di dunia. Menurut laporan organisasi kesehatan dunia World Health Organization (WHO) pada tahun 2015 menunjukkan prevalensi penderita Hipertensi di dunia sekitar 1,13 miliar orang di dunia menderita hipertensi, artinya 1 dari 3 orang di dunia terdiagnosis menderita hipetensi, hanya $36,8 \%$ diantaranya yang minum obat.

Di Indonesia penyebaran penyakit meluas keseluruh lapisan masyarakat jumlah penyakit hipertensi berdasarkan Riskesdas (2018), prevalensi hipertensi di Indonesia sebesar $34,1 \%$ orang yang mengalami hipertensi hanya $1 / 4$ yang terdiagnosis, sisanya 3/4 tidak terdiagnosis. Data menunjukkan hanya $0,8 \%$ orang yang terdiagnosis tekanan darah tinggi minum obat hipertensi.

Kementrian Kesehatan Republik Indonesia (Kemenkes RI,2017) menyatakan prevalensi masyarakat Indonesia dengan hipertensi sebesar 30,9\%. Masyarakat daerah perkotaan juga lebih banyak menderita hipertensi $(31,7 \%)$ jika dibandingkan dengan masyarakat daerah pedesaan $(30,2 \%)$. Hal ini menunjukkan bahwa sebagaian besar penderita hipertensi tidak menyadari menderita hipertensi ataupun mendapatkan pengobatan.

Di Jambi kejadian hipertensi masih menjadi suatu fenomena atau masalah kesehatan yang utama. Dari 10 penyakit terbesar di Kota Jambi, hipertensi termasuk angka kejadian tertinggi. Berikut data dari Dinas Kesehatan Kota Jambi yang menunjukkan 5 penyakit terbesar di Kota Jambi tahun 2018 yaitu Hipertensi sebanyak 13.015 kasus $(46,2 \%)$, kemudian diikuti Diabetes sebanyak 5.245 kasus (18,6\%), Obesitas sebanyak 2.805 kasus $(10,0 \%)$, Asma sebanyak 1.617 kasus $(5,7 \%)$ dan
Cidera akibat kecelakaan lalu lintas sebanyak 1.296 kasus $(4,6 \%)$.

Penyebab terjadinya hipertensi dapat dibedakan menurut jenis hipertensi yaitu hipertensi primer (essensial) merupakan tekanan darah tinggi yang disebabkan karena retensi air dan garam yang tidak normal, sensitifitas terhadap,obestitas, hiperkolesteroemia, emosi yang terganggu/ stress dan merokok. Sedangkan hipertensi sekunder merupakan tekanan darah tinggi yang disebabkan karena penyakit kelenjar adrenal, penyakit ginjal, toxemia gravidarum, peningkatan tekanan intra cranial, yang disebabkan tumor otak, dan pengaruh obat tertentu misalnya obat kontrasepsi (Sarif,2012).

Jumlah pasien kunjungan 6507 orang, perbandingan antara perempuan dan laki-laki bila ditinjau, ternyata hipertensi yang disebabkan oleh pengaruh gaya hidup ini juga lebih banyak terjadi pada wanita. Wanita yang berusia 25-50 tahun pada masa ini sering terjadi perubahan hormonal didalam tubuh yang disebabkan pola hidup yang salah (Yeni dkk, 2010). Jumlah perempuan lebih tinggi dikarenakan hormone esterogen menurun saat menopause, perempuan kehilangan efek menguntungkannya sehingga tekanan darah meningkat (Herbert Benson dkk, 2012). Proses ini terus berlanjut dimana hormone progesterone berubah kuantitas sesuai dengan umur wanita secara alami maka terjadinya hipertensi pada wanita lebih tinggi dibandingkan laki-laki yang diakibatkan faktor hormonal (Anggraini, 2012).

Peran perawat sebagai pemberian perawatan (Care Giver), pembela keluarga (advocate), pendidik, konseling, kolaborasi, peneliti dan pencegahan penyakit (Hidayat,2012). Salah satu peran perawat dalam pencegahan penyakit yaitu mencegah komplikasi hipertensi penanganan dapat dilakukan secara pengobatan farmakologis, pengobatan nonfarmakologis, maupun pengobatan komplementer. Akhir-akhir ini 
banyak orang menyukai pengobatan komplementer, beberapa alasan diantara nya : tidak menggunakan bahan-bahan kimia dan efek penyembuhan cukup signifikan dan salah satu pengobatan komplementer yang dapat menangani hipertensi yaitu terapi bekam (Umar, 2008).

Menurut Kasmui (2014) secara umum bekam dapat dilakukan dengan 2 cara yaitu bekam basah dan bekam kering. Bekam kering yaitu hanya menghisap permukaan kulit, memijat tempat disekitarnya tanpa mengeluarkan darah kotor dan untuk menghilangkan rasa nyeri pada tubuh bagian belakang. Bekam kering dilakukan sebelum dilanjutkan terapi bekam basah yaitu dengan cara sayatan atau tusukan yang mengeluarkan darah statis atau darah kotor.

Menurut El Sayed et al (2013), penusukan saat terapi bekam akan meningkatkan pelepasan nitrat oksida. Aliran darah ke daerah subkutan tempat dimana penusukan dilakukan meningkat, hal ini sejalan dengan produksi nitrat oksida yang akan meningkat pada daerah yang tinggi sirkulasinya. Peningkatan produksi nitrat oksida juga dilaporkan meningkat saat kulit terluka. Oleh karena terapi bekam dapat mendrainase cairan interstisial, menyaring plasma darah yang tinggi akan zat-zat berbahaya (peroksida lemak dan radikal bebas) dan meningkatkan produksi nitrat oksida maka terapi bekam akan bermanfaat dalam penanganan hipertensi.

Bekam basah bermanfaat untuk mengeluarkan semua kotoran dan endapan yang ada di pembuluh darah yang berhubungan dengan peredaran darah. Menurut Ridho (2015) fisiologi dari bekam yaitu kerusakan pada cel mask akibat dari pembekaman akan melepaskan zat seperti serotonin, histamin, bradikinin, slow releasing substance, prostaglandin, prostasiklin. Zat-zat tersebut akan mendilatasi kapiler dan arteriol. Dilatasi kapiler dan arteriol juga dapat terjadi ditempat yang jauh dari tempat pembekaman, sehingga menyebabkan terjadinya perbaikan mikrosirkulasi pembuluh darah. Efek relaksasi yang ditimbulkan pada otot-otot yang kaku menyebabkan terjadinya penurunkan tekanan darah.

Penelitian yang terkait yang pernah dilakukan oleh Ida (2016) yang berjudul "Pengaruh Terapi Bekam Basah Terhadap Tekanan Darah Pada Pasien Hipertensi" dengan 20 orang responden didapatkan bahwa terapi bekam basah memiliki pengaruh yang signifikan terhadap tekanan darah pada hipertensi dengan $\mathrm{p}$ value 0.001 $(<0,05)$ untuk tekanan darah sistolik, kesimpulannya bekam basah dapat mempengaruhi tekanan darah pada hipertensi.

Berdasarkan penelitian yang dilakukan Mega (2017) dengan judul "Pengaruh terapi bekam basah terhadap tekanan darah pada pasien dengan hipertensi grade I di Rumah Sehat Mina" dengan jumlah 24 responden menemukan bahwa ada perubahan tekanan darah selisih nilai ratarata sistol $(4,67)$ dan diastole $(1,79)$ menunjukkan bahwa ada pengaruh terapi bekam basah pada tekanan darah sistolik pada pasien hipertensi grade I dengan $\mathrm{p}$ value $(0,003)<\alpha(0,05)$, dan tidak ada efek terapi bekam basah terhadap tekanan darah diastolik pada pasien hipertensi dengan grade I dengan nilai $p(0,108)>\alpha(0,005)$.

Hasil survey awal yang peniliti lakukan pada tanggal $22-23$ maret 2020 di Rumah perawatan Al Thaf Kota Jambi dengan mewawancarai 7 responden penderita Hipertensi. Hasil wawancara yang didapat diketahui bahwa 4 dari 7 responden belum pernah mendapatkan terapi komplementer, 1 orang pasien mengatakan pernah melakukan terapi bekam basah dan 2 orang lagi pernah melakukan terapi bekam kering tetapi tidak rutin dan pasien merasakan badan terasa lebih ringan, sakit kepala berkurang tidur lebih nyenyak. 7 orang responden mengatakan minum obat 
dan kontrol ketika sakit saja. Penelitian dilakukan di Rumah Perawatan Al-Thaf kota jambi karena berada di pusat kota dan sering dikunjungi peminat terapi bekam basah.

Dari uraian diatas peneliti tertarik untuk melakukan penelitian tentang "Pengaruh Terapi Bekam Basah Terhadap Perubahan Tekanan Darah Pada Pasien Hipertensi di Rumah Perawatan AlThaf Kota Jambi Tahun 2021"

\section{METODE PENELITIAN}

Penelitian ini merupakan penelitian Pre Experimental Design dengan "Two Group Pre Test and Post Test Design" bertujuan untuk mengetahui pengaruh terapi bekam basah terhadap perubahan tekanan darah pada pasien hipertensi di Rumah perawatan Al Thaf Kota Jambi Tahun 2021. Populasi penelitian ini adalah seluruh kunjungan penderita hipertensi primer yang ada di Kota Jambi Tahun 2020 sebanyak 13.015 kasus. Sampel pada penelitian ini sebagian dari jumlah populasi yang tersedia sebanyak 20 orang penderita hipertensi dengan 10 responden kelompok intervensi dan 10 responden kelompok kontrol dilakukan di Rumah perawatan Al Thaf Kota Jambi. Pemilihan sampel dilakukan dengan teknik Purposive sampling. Penelitian ini telah dilaksanakan pada bulan maret sampai juli Tahun 2021. Instrument dalam penelitian ini yaitu pemeriksaan tekanan darah dilakukan menggunakan sphygmomanometer digital. Untuk mengetahui adanya pengaruh dua variabel yang diteliti nilai distribusi normal data menggunakan uji-t test dan data dianalisis dengan menggunakan analisis bivariat dan univariat.

\section{HASIL DAN PEMBAHASAN}

Hasil yang akan diuraikan meliputi hal-hal berikut ini : karakteristik responden berdasarkan usia, univariat dan bivariate.

\section{Tabel 1 Distribusi Frekuensi Responden Kelompok dan Kelompok Kontrol Berdasarkan Usia}

\begin{tabular}{llllll}
\hline No & Umur & \multicolumn{2}{c}{$\begin{array}{l}\text { Kelompok } \\
\text { Intervensi } \\
\end{array}$} & & \multicolumn{2}{c}{$\begin{array}{l}\text { Kelompok } \\
\text { Kontrol } \\
\text { f }\end{array}$} & \% & f \\
\hline 1 & $41-45$ & 0 & 00,0 & 2 & 20,0 \\
2 & $46-50$ & 3 & 30,0 & 2 & 20,0 \\
3 & $\mathbf{5 1}-\mathbf{5 5}$ & $\mathbf{5}$ & $\mathbf{5 0 , 0}$ & $\mathbf{4}$ & $\mathbf{4 0 , 0}$ \\
4 & $56-60$ & 2 & 20,0 & 2 & 20,0 \\
\multicolumn{2}{l}{ Jumlah } & 10 & $100 \%$ & 10 & $100 \%$ \\
\hline
\end{tabular}

Berdasarkan tabel 1 di dapatkan bahwa distribusi responden kelompok intervensi dan kelompok kontrol berdasarkan usia pada pasien hipertensi banyak pada usia 51 - 55 tahun.

Penambahan usia dapat meningkatkan penambahan resiko terjangkitnya penyakit hipertensi. Walaupun penyakit hipertensi bisa terjadi pada segala usia, tetapi sering menyerang orang dewasa yang berusia >35 tahun. Meningkatnya tekanan darah sering bertambahnya usia memang sangat umum. Hal ini disebabkan karena ada perubahan alami pada jantung, pembuluh darah, dan hormon. Namun perubahan ini disertai dengan faktor yang lain bisa memicu terjadinya penyakit hipertensi (Crown,2011).

\section{A. Univariat}

Tabel 2 Gambaran Tekanan Darah Pretest dan Post-test diberikan Terapi Bekam Basah Pada Kelompok Intervensi 


\begin{tabular}{|c|c|c|c|c|c|c|}
\hline Variabel & Mean & Min & Max & SD & $\mathbf{N}$ & Selisih \\
\hline $\begin{array}{l}\text { Pre } \\
\text { Sistole }\end{array}$ & 152,20 & 143 & 166 & 6,941 & 10 & 10,7 \\
\hline $\begin{array}{l}\text { Post } \\
\text { Sistole }\end{array}$ & 141,50 & 136 & 150 & 4,836 & 10 & \\
\hline $\begin{array}{l}\text { Pre } \\
\text { Diastole }\end{array}$ & 100,80 & 95 & 110 & 5,007 & 10 & 12,9 \\
\hline $\begin{array}{l}\text { Post } \\
\text { Diastole }\end{array}$ & 87,90 & 80 & 100 & 6,523 & 10 & \\
\hline
\end{tabular}

Dari tabel 2 Hasil tekanan darah ratarata pre-test diberikan terapi bekam adalah sistole sebesar $152,20 \mathrm{mmHg}$ dan diastole $100,80 \mathrm{mmHg}$ dengan selisih pre-test adalah $10,7 \mathrm{mmHg}$. Hasil tekanan darah rata-rata post-test diberikan terapi bekam basah sistole sebesar 141,50mmHg dan diastole $87,90 \mathrm{mmHg}$ dan selisih post-test adalah $12,9 \mathrm{mmHg}$.

Perubahan ini terjadi dikarenakan otot ventrikel kiri mengalami hipertrofi atau membesar. Terjadilah dilatasi dan pembesaran jantung. Kedua perubahan struktural tersebut bersifat adaptif keduanya meningkatkan volume sekuncup jantung. Pada saat istirahat, respons kompensasi tersebut mungkin memadai, namun dalam keadaan pembebanan, jantung tidak mampu memenuhi kebutuhan tubuh orang tersebut menjadi cepat lelah dan napasnya pendek (Arif,2012).

Tabel 3 Gambaran Tekanan Darah pada kelompok Kontrol

\begin{tabular}{|c|c|c|c|c|c|c|}
\hline Variabel & Mean & Min & Max & SD & $\mathbf{N}$ & $(-)$ \\
\hline Pre Sistole & $\begin{array}{l}148,7 \\
0\end{array}$ & 143 & 158 & 4,900 & 10 & \multirow[t]{2}{*}{0,8} \\
\hline $\begin{array}{l}\text { Post } \\
\text { Sistole }\end{array}$ & $\begin{array}{l}147,9 \\
0\end{array}$ & 142 & 159 & 5,216 & 10 & \\
\hline $\begin{array}{l}\text { Pre } \\
\text { Diastole }\end{array}$ & 97,70 & 92 & 102 & 3,093 & 10 & \multirow[t]{2}{*}{$\begin{array}{c}(-) \\
0,4\end{array}$} \\
\hline $\begin{array}{l}\text { Post } \\
\text { Diastole }\end{array}$ & 98,10 & 94 & 102 & 2,234 & 10 & \\
\hline
\end{tabular}

Dari tabel 3 Hasil tekanan darah ratarata Pre sistole sebesar $148,70 \mathrm{mmHg}$ dan diastole $97,70 \mathrm{mmHg}$ dengan selisih sistole $0,8 \mathrm{mmHg}$ dan selisih diastole $(-0,4) \mathrm{mmHg}$.
Berdasarkan hasil analisa tersebut dapat disimpulkan bahwa tidak terdapat perbedaan signifikan rata-rata tekanan darah pada kelompok kontrol. Meskipun terdapat penurunan rata-rata tekanan darah, akan tetapi secara statistik penurunan yang terjadi tidak signifikan, hal ini dikarenakan tidak diberikan terapi bekam basah pada kelompok kontrol selama penelitian

\section{B. Bivariat}

Tabel 4 Perbedaan Tekanan Darah Pada Pre-test dan Post-test Kelompok Intervensi

\begin{tabular}{lllllll} 
No & Variabel & Mean & SD & SE & $\begin{array}{l}\text { p- } \\
\text { value }\end{array}$ & N \\
\cline { 1 - 4 } 1 & $\begin{array}{l}\text { Pre } \\
\text { Sistole }\end{array}$ & 152,20 & 6,941 & 2.195 & & \\
\cline { 1 - 4 } 2 & $\begin{array}{l}\text { Post } \\
\text { Sistole }\end{array}$ & 141,50 & 4.836 & 1.529 & & \\
\cline { 1 - 4 } 3 & $\begin{array}{l}\text { Pre } \\
\text { Diastole }\end{array}$ & 100,80 & 5,007 & 1.583 & & \\
\cline { 1 - 4 } 4 & $\begin{array}{l}\text { Post } \\
\text { Diastole }\end{array}$ & 87,90 & 6.523 & 2.063 & & \\
& & & & &
\end{tabular}

Hasil analisis pada tabel 4. menunjukkan Hasil statistic T-Test di dapatkan p-value $=0,000<0,05$, maka dapat disimpulkan bahwa setelah pemberian terapi bekam basah ada pengaruh terhadap perubahan tekanan darah Pre-test dan Posttest di Rumah perawatan Al Thaf Kota Jambi kota jambi.

Proses ini terjadi dikarenakan proses mengeluarkan darah kotor dari dalam tubuh saat dilakukan penusukan halus pada kulit, yang menyebabkan berkurangnya volume darah, relaksasi otot serta vasodilatasi yang terdeteksi oleh baroreseptor yang akan diteruskan ke medulla oblongata sehingga mengaktifkan sistem saraf simpatis atau parasimpartis untuk mengembalikan tekanan darah mendekati tekanan darah semula (Thamrin,2012) penanganan hipertensi dapat dilakukan secara pengobatan komplememter.

Tabel 5 Perbedaan Tekanan Darah Pada Pre-test dan Post-test Kelompok Kontrol 


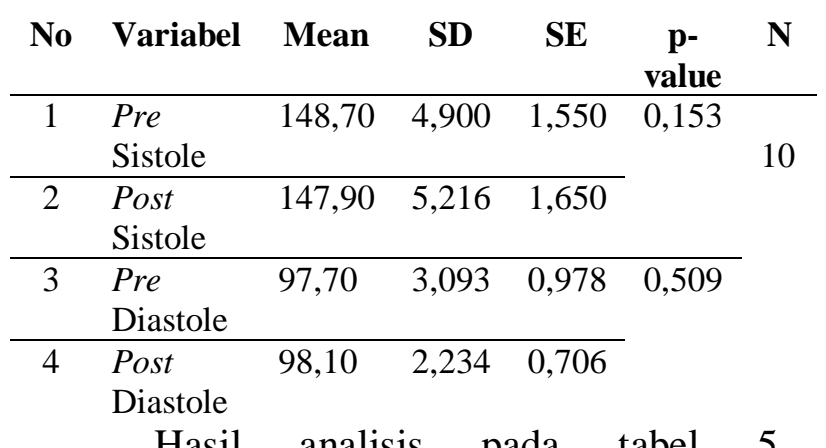
menunjukkan Hasil statistic T-Test di dapatkan $\mathrm{p}$-value sistole $=0,153>0,05$ dan diastole $p=$ value 0,509 , maka dapat disimpulkan bahwa setelah pada kelompok kontrol nilai tidak siginifikan terhadap perubahan tekanan darah di Rumah perawatan Al Thaf Kota Jambi Variasi tekanan darah dapat terjadi bila pasien mengambil posisi yang berbeda-beda. Ketika berdiri pengumpulan darah di vena lebih banyak pada posisi berdiri. Mengakibatkan volume darah yang kembali ke jantung sedikit. Isi sekuncup berkurang, curah jantung berkurang, dan kemungkinan tekanan darah akan turun sedangkan ketika duduk membuat tekanan cenderung stabil. Hal ini dikarenakan pada saat duduk sistem vasokontraktor simpatis terangsang melalui saraf rangka menuju otot-otot abdomen. Hal tersebut membuat darah yang tersedia bagi jantung untuk di pompa menjadi meningkat. Kerja jantung pada posisi duduk, dalam memompa darah akan keras karena melawan gaya gravitasi sehingga kecepatan denyut jantung meningkat.

\section{Perbedaan Selisih Kelompok Intervensi dengan Kelompok Kontrol Pada Pasien Hipertensi di Rumah perawatan Al Thaf Kota Jambi}

Tabel 6 Rata-Rata Sistole Kelompok Intervensi dan Kelompok Kontrol .

\begin{tabular}{lllllcl} 
No & Variabel & Mean & SD & SE & $\begin{array}{c}\mathbf{P} \\
\text { value }\end{array}$ & N \\
\cline { 1 - 5 } $\mathbf{1}$ & Intervensi & 10,70 & 4,498 & 1,422 & & \\
& Kontrol & 0,80 & 1,619 & 0,512 & 0.000 & 10
\end{tabular}

Rata-rata Tekanan darah sistole pada hipertensi kelompok intervensi adalah 10,70 dengan standar deviasi 4,498. Pada kelompok kontrol didapatkan rata-rata tekanan darah adalah 0,80 dengan standar deviasi 1,619 . Terlihat perbedaan nilai mean antara kelompok intervensi dan kelompok kontrol adalah 9,9. Hasil uji statistic didapatkan nilai 0,000 maka dapat disimpulkan ada perbedaan yang signifikan tekanan darah rata-rata sistol antara kelompok intervensi dan kelompok kontrol.

Tabel 7 Rata-Rata Diastole Kelompok Intervensi dan Kelompok Kontrol.

\begin{tabular}{lllllll} 
No & Variabel & Mean & SD & SE & $\begin{array}{c}\mathbf{P} \\
\text { value }\end{array}$ & N \\
\cline { 1 - 5 } $\mathbf{1}$ & Intervensi & 12,40 & 4,671 & 1,477 & & \\
& Kontrol & 0,50 & 1,958 & 1,958 & 0.000 & 10
\end{tabular}

Rata-rata Tekanan darah diastole pada hipertensi kelompok intervensi adalah 12,40 dengan standar deviasi 4,671. Pada kelompok kontrol didapatkan rata-rata tekanan darah adalah 0,50 dengan standar deviasi 1,958 . Terlihat perbedaan nilai mean antara kelompok intervensi dan kelompok kontrol adalah 11,9. Hasil uji statistic didapatkan nilai 0,000 maka dapat disimpulkan ada perbedaan yang signifikan tekanan darah rata-rata diastole antara kelompok intervensi dan kelompok kontrol.

\section{SIMPULAN}

Terjadi penurunan rata-rata tekanan darah pada pasien hipertensi setelah diberikan terapi bekam basah. Hal ini menunjukkan bahwa terapi bekam basah memiliki efek yang bak terhadap tekanan darah pada pasien hipertensi. terdapat perbedaan signifikan rata-rata tekanan darah antara kelompok intervensi dan kelompok kontrol. Dengan demikian dapat disimpulkan bahwa terapi bekam basah memiliki pengaruh dalam menurunkan tekanan darah pada pasien hipertensi. 


\section{SARAN}

Penelitian ini diharapkan dapat menjadi tambahan informasi mengenai terapi komplementer, khususnya pada terapi bekam basah, sehingga diharapkan dalam pemberian asuhan keperawatan sebagai salah satu pencegahan penyakit hipertensi.

Penelitian ini dapat menjadi acuan untuk penelitian selanjutnya, diharapkan agar dapat lebih membuktikan terapi bekam basah dengan lebih lama waktu pada penelitian, dan jumlah responden yang lebih banyak.

\section{DAFTAR PUSTAKA}

Anggarini. 2012. Pelayanan Keluarga Berencana. Yogyakarta: Rohima Press.

Asosiasi Bekam Indonesia. (2011). Standard Operating Procedure Bekam. Bogor: Bidang Penelitian dan Pengembangan ABI.

Bararah, Tarqiyyah. (2013). Asuhan Keperawatan Panduan Lengkap Menjadi Perawat Profesional. Jakarta: Prestasi Pustakaraya

Benson, dkk. (2012). Menurunkan Tekanan Darah. Jakarta: Gramedia.

Budi. (2015). Faktor-Faktor Yang Berhungan Dengan Kejadian Hipertensi Tidak Terkendali Pada Penderita Yang Melakukan Pemeriksaan Rutin di Puskesmas Kedungmundu Kota Semarang. Kesehatan Masyarakat Universitas Negeri Malang.

Caroline. B.R., and Mary, T.K. (2017). Textbook Of Basic Nursing, Edisi 10. Anisa E. Wuri P, Penerjemah. (2012). Buku Ajar Keperawatan Dasar. EGC, Jakarta

Crown,E. (2011). Buku Saku Patofisiologi. Alih Bahasa Brahm U, Pendit, EGC, Jakarta

Dahlan,M.Sopiyudin, (2011). Statistik untuk kedokteran, dan kesehatan: Deskriptif, Bivariat, dan Multivariat. Jakarta: Salemba Medika.

Endah. (2017). Pengaruh Terapi Bekam Basah Terhadap Tekanan Darah Pada
Pasien Hipertensi. Tesis. Stikes Kendedes, Malang

Gray, Huon. (2005). Lecture Notes on Cardiology, Edisi keempat. Agoes, Azwar, Penerjemah (2003). Lecture Notes: Kardiologi. Erlangga.

Hidayat \& Uliyah. (2012). Konsep Dasar Manusia. Surabaya : Health book publishing

Hurst, Marlene. (2016). Medical-surgical nursing review, Volume 1. Komara E. Devi Y, Penerjemah. (2011). Keperawatan Medikal-Bedah. Jakarta: EGC

Ida. (2016). Pengaruh Terapi Bekam Basah Terhadap Tekanan Darah Pada Pasien Hipertensi. Universitas Muhammadiyah, Tasikmalaya.

Jansje H, V. Ticoalu \& Yoseph L Samodra. "Prevalensi Penyakit Tidak Menular Pada Tahun 2012-2013 di Kecamatan Airmadidi Kabupaten Minahasa Utara Sulawesi Utara" Diakses pada tanggal 3 juli 2015 dari http://jkesmasfkm.unsrat.ac.id/wp-

Kasmui. (2010). Bekam Pengobatan Menurut Sunah Nabi, Semarang: Komunitas Thibbun Nabawi "ISYFI".

Kemenkes RI. Hipertensi. Infodatin Pusat Data dan informasi Kementrian Kesehatan RI. 2017.

Mega. (2017). Pengaruh Terapi Bekam Basah Terhadap Tekanan Darah Pada Pasien Dengan Hipertensi Grade I Di Rumah Sehat Mina. Universitas Riau, Riau.

Muttaqin, Arif (2012). Asuhan Keperawatan Klien dengan Gangguan Sistem Kardiovaskular. Jakarta: Salemba Medika

Nair, Muralitharan. (2015). Dasar-Dasar Patofisiologi Terapan. Jakarta: Bumi Medika

Notoatmodjo. (2012). Metodologi Penelitian Penelitian Kesehatan. Jakarta: Rineka Cipta 
Nursalam. (2017). Metodologi Penelitian Ilmu Keperawatan. Jakarta: Salemba Medika

Ridho, Achmad (2015). Bekam Sinergi. Solo: PT Aqwam Media Profetika

Rosidawati, dkk. (2016). Pengaruh Terapi Bekam Terhadap Tekanan Darah Pada Pasien Hipertensi di Rumah Sehat Cordova Kota Tasikmalaya.

Sarif. (2012). Asuhan Keperawatan Gerontik. Yogyakarta: Nuha Medika

Shaaban T. (2009). Cupping Therapy in Brief

Siswanto,dkk. 2013. Metodologi Penelitian Kesehatan dan Kedokteran, Yogyakarta, Bursa Ilmu.

Sugiyono. (2017). Metode Penelitian Kuantitatif, Kualitatif, dan R\&D. Bandung: Alfabeta,CV.

Susiayanto, Azib (2013). Hijama or Oxidant Drainage Therapy. Jakarta: Gema Insani

Supayanto. (2011). Wanita Usia Subur (WUS).

http://id.wikipedia.org/wiki/promosikese hatan.

Sutanto. (2010). Awas Tujuh Penyakit Degeneratif. Yogyakarta: Paradigma Indonesia

Syamsudin (2011). Buku Ajar Farmakoterapi Kardiovaskular dan Renal. Jakarta: Salemba Medika

Trianto. (2014). Pelayanan Keperawatan Bagi Penderita Hipertensi Secara Terapadu. Yogyakarta: Graha Ilmu

Umar, Wadda. (2012). Sembuh dengan Satu Titik Bekam untuk 7 penyakit kronis. Solo: Thibbia

World Health Organization (WHO), 2015. Data Hipertensi Global, Asia Tenggara: WHO.

Yeni Yufita, dkk. (2010). Faktor-Faktor Yang Berhubungan Dengan Kejadian Hipertensi Pada Wanita Usia Subur di Puskesmas Umulharjo I. Fakultas Kesehatan Masyarakat Universitas Ahmad Dahlan. Yogyakarta
Yogie,dkk. (2018). Pengaruh Terapi Bekam Kering Terhadap Tekanan Darah Pada Lansia Dengan Hipertensi di PTSW Jember.

Yufi Aris, dkk. (2017). Pengaruh Terapi Bekam Terhadap Perubahan Tekanan Darah Pada Penderita Hipertensi di Dusun Tambak Rejo Desa Gayaman Mojokerto. 